\section{A socialização da medicina na era do adhemarismo*}

\section{The socialization of medicine in the era of São Paulo Governor Adhemar de Barros}

Fabio de Oliveira Almeida

Doutorando, Programa de Pós-graduação em Sociologia/ Universidade Federal de São Carlos.

Rodovia Washington Luís, km 235

13565-905 - São Carlos - SP - Brasil

fabioliveiral@yahoo.com.br

Recebido para publicação em abril de 2012.

Aprovado para publicação em março de 2013.
ALMEIDA, Fabio de Oliveira. A socialização da medicina na era do adhemarismo. História, Ciências, Saúde - Manguinhos, Rio de Janeiro, v.21, n.4, out.-dez. 2014, p.1379-1396.

\section{Resumo}

A análise observa as conexões entre o processo de profissionalização dos médicos paulistas e políticas de saúde do governo estadual de Adhemar de Barros em São Paulo (1947-1951), em meio a amplas mudanças na área de saúde denominadas pelos médicos paulistas "socialização da medicina". Reconhecemos aspectos ambivalentes para o profissionalismo médico diante desse governo populista, como: a luta médica pela equiparação ante os advogados servidores públicos estaduais; a criação de uma secretaria de saúde estadual; e certos elos contraditórios entre a área de saúde adhemarista e a ideologia e a organização profissionais da medicina paulista. Nesse particular, o artigo aprofunda a análise de manifestações ideológicas de importantes lideranças médicas paulistas.

Palavras-chave: socialização da medicina; adhemarismo; profissionalismo.

\section{Abstract}

The article analyzes how the process of the professionalization of physicians in São Paulo related to healthcare policy under the administration of São Paulo governor Adhemar de Barros (1947-1951) during a period of broad change in the realm of health known by São Paulo physicians as the "socialization of medicine." Medical professionalism confronted certain ambivalences under this populist administration, including doctors' struggle to achieve pay equal to that of state public attorneys; the establishment of a state health department; and some contradictory ties between the area of health under Adhemar and the professional ideology and organization of medicine in São Paulo. The article undertakes a more in-depth analysis of the ideological manifestations of important leaders in the state's medical community.

Keywords: socialization of medicine; Adhemarism; professionalism. 
$\mathrm{E}^{\mathrm{n}}$ ntre 1940 e 1950, a medicina experimentou relevantes desenvolvimentos tanto de natureza uprofissional como científica, tecnológica e organizacional mais abrangentes, os quais se iniciaram antes, particularmente desde o século XIX, e que assumiram contornos específicos em distintas partes do mundo, especialmente depois da Segunda Guerra Mundial. Esses desenvolvimentos alteraram as relações entre medicina, sociedade e Estado e implicaram processos de diferenciação tanto de organizações e serviços de saúde como de especialidades profissionais, com desdobramentos na iniciativa privada e nas políticas estatais, envolvendo mudanças na saúde pública e na assistência médica. Houve maior ênfase ao trabalho desenvolvido por equipes de profissionais, realizado em contexto organizacional (hospitalar e/ou ambulatorial), além de ampliação da participação estatal no setor, conforme o caso (Freidson, 2009; Porter, 2008).

Tais mudanças foram assimiladas à peculiar realidade brasileira de tal modo que, neste artigo, as acompanhamos em relação ao seu impacto junto à área de saúde do estado de São Paulo, especialmente em meio ao desenvolvimento de políticas públicas de saúde pelo governo paulista, durante o mandato de Adhemar Pereira de Barros como governador do estado (19471951). Tal governo populista (French, 1995) foi caracterizado, na área de saúde, pela criação de uma Secretaria de Saúde Pública e Assistência Social, pelo estabelecimento de delegacias regionais de saúde e expansão de centros de saúde e postos sanitários no interior do estado. Além disso, foi marcante pelas contraditórias relações entre médicos e governo em torno da luta pela equiparação econômico-jurídica de médicos e engenheiros com os advogados servidores públicos estaduais, os quais, à época, recebiam vencimentos superiores aos outros profissionais na mesma condição. Ademais, durante esse período ocorre a interiorização da Associação Paulista de Medicina (APM), principal entidade médica paulista da época, rumo a diversas regiões do estado, em um movimento relativamente paralelo ao da configuração da nova secretaria de saúde. Entendemos que tais circunstâncias implicaram um contexto desafiador, mas que também serviu de impulso ao processo de fortalecimento coletivo da medicina paulista. Na esteira dessas mudanças, em meio a um amplo processo internacional denominado pelos próprios médicos paulistas "socialização da medicina" - que implicava a maior participação de organizações estatais e paraestatais nos serviços de saúde -, a criação da referida secretaria sinalizou uma ampliação das estruturas estatais de assistência à saúde e um crescimento do mercado de trabalho para esses médicos, que passaram a contar com um organismo público mais especializado em seu âmbito profissional.

Nessas circunstâncias, talvez fosse possível afirmar que os médicos da clínica privada representassem interesses relativamente distintos dos médicos ligados à administração governamental, e que talvez tivessem se relacionado de maneira diversa com as políticas de saúde adhemaristas: de um modo aparentemente mais crítico que os profissionais ligados à iniciativa privada, que passaram a atuar sob a concorrência dos novos serviços sanitários; e de um modo, possivelmente, mais favorável aos médicos sanitaristas e profissionais ligados à administração pública, visto, a priori, terem se beneficiado com o sentido das políticas adhemaristas. Tais distinções do campo médico paulista se situavam em um contexto muito particular, em função de a saúde pública estadual ter adquirido um espaço maior desde a Primeira República (Castro Santos, 2004; Hochman, 1998). Por outro lado, a medicina de grupo, que também realiza trabalhos em equipes de especialistas dentro de organizações 
de saúde, igualmente atravessava significativos desenvolvimentos no período estudado. Enfim é preciso mencionar o crescimento da medicina previdenciária, que após 1930 teve sua esfera de atuação ampliada, dada a maior atenção do Estado brasileiro aos trabalhadores urbanos (Oliveira, Teixeira, 1985; Schraiber, 1993).

Contudo, ao analisar dados da época publicados no jornal O Estado de S. Paulo e na Revista Paulista de Medicina (da APM), verificamos ações políticas e posicionamentos ideológicos dos médicos paulistas que suavizam bastante a aludida oposição intraprofissional. Acreditamos que, diante dos fatores mencionados acima e da análise que se segue, ao longo do governo estudado, os médicos paulistas experimentaram uma considerável relativização de suas diferenças e oposições internas e um reforço da coesão do grupo para enfrentamento dos desafios de seu tempo. Este artigo procura evidenciar não apenas essa realidade, mas, ainda que particularmente quanto à sua relação com as políticas de saúde estaduais e à mencionada socialização mais abrangente da medicina, que os médicos de São Paulo apresentaram uma postura também ambivalente frente ao governo populista de Adhemar de Barros.

\section{Populismo e profissionalismo médico}

De uma perspectiva mais geral, muitas vezes o populismo tem sido discutido como um fenômeno político brasileiro característico dos anos entre 1930 e 1964, sendo-lhe peculiar a emergência das massas populares como relevantes atores políticos, em um contexto de crise de hegemonia entre as classes dominantes e autonomização do poder de Estado junto à sociedade (Weffort, 1978; Saes, 1985). Nesse enquadramento, o conceito de massas vem sendo empregado em seu sentido marxista original, ou seja, como classes sociais de comportamento político heterônomo e relações sociais amorfas, o que relativizaria os termos da influência política dos grupos populares, que assim permaneceriam sob a tutela e manipulação política estatal e das chamadas lideranças populistas.

No entanto, conforme Ferreira (2001), outros pesquisadores têm sido críticos dessa visão dicotômica desigual e sem interlocução entre Estado e sociedade. Sem rejeitar o conceito de populismo de uma forma mais ampla, autores como John French (1995) propõem outro eixo explicativo, que destaca as relações entre as classes sociais e o Estado populista como relações de aliança: assim, as relações entre trabalhadores, Estado, classes médias e burguesia se teriam constituído em termos de interlocução e alianças que, embora estabelecidas entre atores desiguais do ponto de vista sociopolítico, não prescindiram de conflitos ou negociações. Tais alianças não seriam apenas bilaterais, mas parte de um sistema contraditório de alianças de cada um dos grupos envolvidos. Com efeito, entendemos que a estrutura de poder populista possibilita a investigação não apenas das classes tomadas como agregados estanques, mas também o estudo das relações de aliança entre setores ou grupos sociais determinados, que assim integram uma mesma classe e se caracterizam por lógicas sociopolíticas relativamente peculiares e específicas que não se encontram direta e imediatamente subsumidas à lógica das relações de classes.

Em nossa análise, acompanhamos as relações de aliança entre alguns setores de classe média paulista e o Estado populista, quais sejam, determinados grupos médicos, em termos de suas alianças com o poder de Estado em São Paulo durante o governo de 
Adhemar de Barros. Tais relações marcaram o processo de profissionalização dos médicos paulistas. Questionamos como tais grupos sociais, presentes na estrutura sociopolítica de São Paulo, relacionaram-se com essa expressão de liderança populista. Nesse ínterim, são valiosas as contribuições de Eliot Freidson (2001) sobre o profissionalismo e os processos de profissionalização. Segundo o autor, o profissionalismo sustenta-se na valorização do mérito e da expertise profissionais, alegando que, nessas condições, os profissionais atuam de maneira autônoma tanto da clientela como dos patrões, na defesa de valores transcendentes - como a "saúde", que tem sido amplamente defendida como um importante valor social pela medicina.

Freidson não nega, mas reconhece a existência de interesses profissionais específicos; contudo, em vez de salientar um possível sentido meramente usurpador de poder nas estratégias profissionais, destaca também suas estratégias de autoproteção, conquista e manutenção de autonomia profissional frente às influências e interferências externas. Assim, a autonomia técnico-profissional permitiria aos profissionais oferecer serviços de melhor qualidade e com independência à sociedade e ao Estado. $\mathrm{O}$ conceito de autonomia carregaria: "Duas implicações bem diferentes - autonomia 'da' influência ou poder de outros, e autonomia 'para' influenciar ou exercer poder sobre outros" (Freidson, 2009, p.410; destaque meu). Como conceito sociológico, o profissionalismo reuniria as características institucionais e ideológicas dos grupos ocupacionais organizados sob sua lógica. Em São Paulo, podemos observar tais características em relação às condições da medicina paulista durante o governo adhemarista.

Os médicos de São Paulo realizavam atividades laborais especializadas, sustentadas por conhecimentos técnico-abstratos discricionários (expertise), e ocupavam um importante espaço na força de trabalho. Eram médicos generalistas, sanitaristas e especialistas clínicos e/ou cirurgiões que dominavam conceitos, métodos e técnicas para a realização de diagnósticos e tratamentos de diversas enfermidades. Tais médicos controlavam uma jurisdição exclusiva e ocupavam posição dominante nos hospitais, serviços sanitários e demais organizações de saúde. Mantinham credenciais profissionais exclusivas em instituições de formação de nível superior, que transmitiam conhecimentos, formavam e credenciavam profissionais, como: Faculdade de Medicina e Faculdade de Higiene e Saúde Pública, ambas da Universidade de São Paulo (USP), e Escola Paulista de Medicina. Enfim, esse grupo cultivava uma ideologia que primava mais pelo compromisso com a realização de seu trabalho com qualidade que sua eficiência econômica: notável tanto em críticas de lideranças associativas à influência negativa de interesses econômicos privados sobre a área de saúde como em divergências com organismos estatais - que não nutririam condições apropriadas ao seu trabalho nem ao atendimento à população. Apesar dessas críticas, o compromisso com valores socialmente superiores também se expressava na justificação de maior participação do Estado na área de saúde, a despeito do consequente e nem sempre bem-vindo assalariamento de profissionais (Ramos, 1949).

Encontramos, portanto, linhas de convergência entre traços específicos do aludido conceito de profissionalismo e significativas características da medicina paulista, que possuía considerável autonomia técnica e permanecia em peculiares condições de interlocução com o estado adhemarista. 
De acordo com Terence Halliday (1999), em sua relação com o Estado, os profissionais não apenas produziriam expertise àquele, mas, embasados na neutralidade do conhecimento, organizar-se-iam em nome da sociedade civil para defendê-la da autoridade estatal, em favor do bem comum: é o que ele denomina profissionalismo cívico. Halliday não exclui a existência de interesses jurisdicionais na atuação profissional nem interesses por status ou benefícios econômicos e políticos. $\mathrm{O}$ autor acredita que as motivações do agir profissional implicam um complexo amálgama de orientações que difere conforme o contexto político, econômico ou profissional. Mas, ao lado dessas motivações, o sociólogo encontra uma motivação cívica, centrada na neutralidade da técnica e em suas distinções sobre a política partidária, a fim de preservar o âmbito profissional das influências políticas externas prejudiciais à sua posição na sociedade.

Halliday percebe uma tensa coexistência entre o que ele chama de centro da profissão, ou elite, com perfil mais conservador, e a periferia, ou base, mais engajada politicamente. O primeiro grupo mantém uma fronteira mais rígida entre o aspecto técnico-profissional e o político-partidário; já o segundo tende a mesclar ambos os aspectos. Essa polaridade permite-nos fazer uma aproximação da teoria de Halliday com a teoria formulada por Pierre Bourdieu acerca do conceito de campo: "[este] se define como o locus onde se trava uma luta concorrencial entre os atores em torno de interesses específicos que caracterizam a área em questão" (Ortiz, 1983, p.19), em que se notam posições de poder em função da distribuição desigual de um quantum social em seu interior, que o autor chama de capital social, sendo o eixo fundamental da estrutura do campo constituído por dominantes e dominados. Assim, o grupo dominante estabelece práticas ortodoxas de conservação do capital acumulado, ao passo que o outro utiliza práticas sociais heterodoxas, a fim de desacreditar o poder de seus rivais.

No campo profissional, como da medicina, a autonomia técnica representa a base de seu poder e fonte principal de sua dinâmica e lutas internas. Parte importante da fundamentação dessa autonomia advém da preservação de certa neutralidade técnica diante da influência político-partidária. Isso constitui uma espécie de ortodoxia, à qual se contrapõe uma heterodoxia - representada pela postura que aproxima a expertise profissional de um maior engajamento político. No caso dos médicos de São Paulo, verificamos como lidaram com os dilemas relacionados à influência política do adhemarismo, responsável pelo desenvolvimento de políticas de saúde com significativas implicações no profissionalismo médico. Considerada essa relação do ponto de vista das conexões entre neutralidade técnica e política, observamos ambivalências entre a medicina e o adhemarismo. Verificamos, ainda, como observado, certa relativização das oposições internas aos médicos - em termos de hierarquia de poder e entre os diversos setores e especialidades -, a fim de esse grupo se fortalecer e enfrentar as mudanças setoriais que acompanham o período.

\section{A saúde adhemarista e a medicina de São Paulo}

As políticas de saúde de Adhemar de Barros ora impulsionaram a autonomia profissional médica (Freidson, 2009), ora atuaram negativamente, e foram empreendidas em um conturbado ambiente, marcado por contraditórias relações entre as partes em torno da conhecida "questão de equiparação", que se estendeu ao longo desse governo. Esse episódio 
implicou a tentativa do grupo médico paulista de equiparar-se jurídica e economicamente ao grupo dos advogados que trabalhavam para o Departamento Jurídico do Estado de São Paulo e que recebiam vencimentos superiores aos médicos servidores estaduais.

Essa luta, entre momentos de aproximação e distanciamento com o governo Adhemar, aproximou a medicina da categoria dos engenheiros que também trabalhavam para o mesmo governo. Aliados, criaram o "Movimento de Assembleia Permanente de Médicos e Engenheiros", que lutou pela equiparação. O movimento, embora inicialmente bem recebido pelo governo paulista, que chegou a prometer a realização da desejada mudança, entrou em forte atrito com Adhemar e com a Assembleia Legislativa estadual, por conta do posterior desinteresse do governo de atender à sua demanda e em razão do polêmico projeto de lei n.209, o qual propunha, entre outras questões, a mencionada equiparação. O governador e médico Adhemar de Barros chegou a ser considerado inimigo da categoria médica; deputados estaduais e profissionais mobilizados desentenderam-se e apenas reataram o diálogo por interferência do arcebispo de São Paulo da época, dom Carlos Carmelo de Vasconcelos Mota. Além disso, essa mobilização produziu uma greve que levou colegas de profissão a excluir de suas associações os profissionais contrários à mesma. No entanto, embora o polêmico projeto tenha sido aprovado e sancionado pelo poder público, foi acompanhado de um veto que excluiu de seu texto a pretendida equiparação. Se, do ponto de vista da autonomia e neutralidade técnicas, os médicos restringiram seu âmbito de influência, ameaçando não oferecer seus serviços aos deputados contrários às suas demandas e entrando em atrito com colegas de profissão, por outro lado, esse movimento fortaleceu a coletividade médica, beneficiando sua autonomia profissional pela extensão de sua organização política estadual, pois mobilizou distintas entidades - como a Associação Paulista de Medicina, a Sociedade de Medicina e Cirurgia de São Paulo e o Sindicato Médico de São Paulo - e criou vários núcleos do movimento no interior.

A questão da equiparação revelou apenas uma faceta das ambivalências entre os médicos e o governo estadual. No processo de criação e organização, em 1947, da nova Secretaria de Saúde Pública e Assistência Social, notamos um relativo movimento pendular que oscilou entre considerável instabilidade e politização do comando dessa secretaria e a promoção de uma reforma nos serviços de saúde estaduais. Do ponto de vista da autonomia profissional, de um extremo a outro desse movimento pendular também evidenciaram-se ambivalências nas relações entre a medicina paulista e o adhemarismo.

Tal instabilidade se relacionava a um agitado contexto político que acompanhou esse governo. Desde o início de seu mandato, Adhemar de Barros promoveu significativas alterações em seu secretariado causadas por motivações político-partidárias. Várias dessas mudanças aconteceram em função da instabilidade política do governo, marcado por forte oposição da União Democrática Nacional (UDN), do Partido Social Democrático (PSD) e até do Partido Trabalhista Brasileiro (PTB) (Sampaio, 1982). Nesse contexto, negociações políticas que implicaram tentativas do governo de contornar tais crises produziram alterações no seu secretariado.

Seja por razões partidárias ou não, apenas no ano de 1947, o titular da pasta da Saúde é substituído várias vezes. Além disso, outros ocupantes de cargos importantes na Secretaria de Saúde são substituídos, como os diretores do Departamento de Profilaxia da Lepra, do 
Instituto Butantã e do Departamento de Saúde. Com efeito, deve-se observar que, quanto ao cargo mais importante da administração sanitária paulista entre 1889 e 1947 - isto é, diretor sanitário (primeiramente) e secretário da Saúde (mais tarde) -, a tendência de instabilidade e mudança de comando típica do governo adhemarista contrasta com a tendência no setor ao longo da Primeira República: enquanto, nesse período, houve em São Paulo um diretor do Serviço Sanitário como Emílio Ribas, que permaneceu no cargo durante quase vinte anos, no governo de Adhemar de Barros as substituições de secretários se estenderam além do primeiro ano de mandato.

Essa instabilidade política não se restringiu à questão das trocas de secretários ou diretores de departamentos. Verificou-se, ainda, em dois polêmicos episódios. O primeiro, que ficou conhecido como "o caso do Hospital das Clínicas", diz respeito à cizânia em torno do orçamento do governo e o impacto, para as contas públicas, das verbas destinadas ao Hospital das Clínicas da USP. Esse evento repercutiu não somente na imprensa como também entre os grupos políticos, servindo como mais uma fonte de atritos entre situação e oposição estaduais (O Estado..., 26 jan. 1949, p.3; 30 jan. 1949, p.3; 16 fev. 1949, p.4). A comissão da Assembleia Legislativa responsável pela questão não teria seguido aquilo que o governo paulista desejava e apresentou um orçamento maior para o Hospital das Clínicas que o governo pretendia - grupos políticos adhemaristas culparam a UDN pelo acontecimento.

O outro episódio deveu-se a um processo de transferências e relotação de funcionários ocorrido no Instituto Butantã, em 1948, fato que gerou manifestações políticas significativas da oposição na Assembleia Legislativa. Em sessão noturna relatada pelo jornal O Estado de S. Paulo, em 6 de fevereiro de 1948, o deputado oposicionista Ernesto Pereira Lopes (UDN) criticou mudanças de funcionários, as quais teriam prejudicado os trabalhos da instituição. Mas as acaloradas discussões entre oposição e situação se prolongaram ainda mais e tomaram boa parte daquela sessão noturna da Assembleia Legislativa. Houve outros processos de relotação de funcionários no governo Adhemar que alteraram relativamente sua configuração interna, mas nenhum gerou tanta polêmica.

Toda essa instabilidade levou médicos paulistas a demandar a permanência de um profissional da área para o comando da Secretaria de Saúde, escolhido essencialmente por critério técnico, algo talvez difícil naquelas circunstâncias. Acreditamos que essa instabilidade decorreu em parte do fato de Adhemar ter-se desentendido com forças políticas tradicionais do estado, criando um ambiente mais hostil para seu governo. Além disso, é inegável que houve uma transição que reorganizou os serviços de saúde, culminando na criação da Secretaria de Saúde Pública e Assistência Social, produzindo um contexto de mudanças com fortes implicações políticas.

A Secretaria de Negócios da Saúde Pública e Assistência Social foi criada pelo decreto-lei n.17.339, assinado em 28 de junho de 1947. Com essa secretaria, embora os médicos tivessem obtido uma relevante conquista para sua autonomia profissional em âmbito estadual, tiveram de enfrentar significativa politização da mesma, o que representou um desafio ao grupo médico do ponto de vista do profissionalismo, pois a constituição da secretaria foi acompanhada de um campo de tensões e conflitos em torno das fronteiras entre política e neutralidade técnico-profissional (Halliday, 1999). 
Da antiga Secretaria de Educação e Saúde Pública, foram transferidos para a nova Secretaria de Saúde os departamentos de Saúde, de Assistência a Psicopatas, o Estadual da Criança e o da Profilaxia da Lepra e, ainda, os Serviços de Pênfigo Foliáceo e de Medicina Social, o Instituto Butantã e o Serviço Social do Estado. A essa estrutura também se acoplaram os centros de saúde, postos de higiene e subpostos estaduais. Ademais, incorporaram-se as instalações hospitalares e santas casas ligadas ao governo. Além de criar essa nova secretaria, o governo desenvolveu outras organizações que passaram a estruturá-la internamente. Foi estabelecida a Divisão Sanitária do Estado de São Paulo, em conformidade com o que havia determinado antes o decreto-lei n.17.030, de 6 de março de 1947, o qual também organizou, integrada ao Departamento de Saúde, a Divisão do Serviço do Interior, instituindo uma diretoria com sede na capital, 304 unidades sanitárias espalhadas pelo estado e mais 19 delegacias regionais de saúde. A Divisão do Serviço do Interior deveria administrar e fiscalizar os serviços da sede, das delegacias e dos centros de saúde e postos médico-sanitários. Já as delegacias de saúde deveriam cuidar dos serviços da sede e das unidades sanitárias sob sua jurisdição.

Os cargos criados e vinculados às unidades sanitárias por esse decreto foram: médico sanitarista, médico em função gratificada responsável pela administração da própria unidade sanitária, educador sanitário, inspetor sanitário, fiscal sanitário e escriturário, além de técnico de laboratório, prático de laboratório, atendente, servente, assistente dos dispensários e ambulatórios, e anatomopatologista. Para cargos de comando, como chefes de subdivisão, inspetores técnicos e delegados de saúde, deveriam ser designados médicos nomeados que integrassem o quadro de servidores efetivos da Divisão do Serviço do Interior e que já tivessem exercido função de assistente técnico ou congênere, ou de chefia, ou que tivessem sido admitidos por concurso, ou, ainda, médicos com especialização em higiene ou saúde pública. Nesse sentido, podemos perceber como os médicos assumiram posições centrais na configuração hierárquica da secretaria e a preferência por médicos que estivessem efetivamente vinculados ao serviço público. De certo modo, os médicos passaram a ocupar posições centrais não apenas nas equipes técnicas, mas, igualmente, nos cargos de caráter político-administrativo, como os de delegados de saúde. Diante disso, parece evidente que a preferência por médicos, particularmente funcionários efetivos e não nomeados puramente por indicação política, demonstra como, do ponto de vista profissional, os médicos paulistas foram também favorecidos por essas mudanças. Isto é, do ponto de vista da autonomia profissional (Freidson, 2001), os médicos tiveram sua posição de controle e poder sobre seu ambiente de trabalho fortalecida dentro da Secretaria de Saúde.

Quanto às delegacias regionais de saúde, teriam ordenação numérica crescente, localizando-se a primeira na capital e as outras nas seguintes cidades-sedes interioranas: Taubaté, Guaratinguetá, Santos, Itapetininga, Santa Cruz do Rio Pardo, Presidente Prudente, Marília, Lins, São José do Rio Preto, Araraquara, Ribeirão Preto, Casa Branca, Campinas, São Carlos, Bauru, Botucatu, Sorocaba e Barretos. No que se refere às unidades sanitárias, houve uma distribuição que atingiu as mais diferentes regiões interioranas, em um movimento de expansão que ocorreu em mais de uma oportunidade, extrapolando posteriormente o número inicial de 304 novas unidades. 
Com isso, podemos perceber como o governo adhemarista, a despeito do considerável nível de politização do comando da Secretaria de Saúde, desenvolveu políticas específicas que alteraram as organizações internas dessa pasta, de modo a oferecer-lhe mais capilaridade junto aos diferentes territórios do estado. Mesmo sendo difícil averiguar, com nossos dados, a efetividade, a eficácia ou a eficiência desses serviços, é possível perceber um desenho institucional que esteve direcionado para a sua expansão rumo ao interior. Por outro lado, tal direcionamento talvez revele outra dimensão do adhemarismo e de sua relação com os médicos do estado, pois o desenvolvimento de estruturas de saúde no interior certamente implicou negociações políticas entre o governo e os grupos políticos situados nas diferentes localidades do interior, com reflexos indiscutíveis na realidade profissional dos médicos atuantes nessas áreas - não sem razão, durante esse governo, o adhemarismo estendeu o seu raio de ação, com vitórias eleitorais em todo o estado (Sampaio, 1982). Essa difusão de estruturas sanitárias representou a emergência de novas variáveis para a configuração do trabalho médico interiorano, para a definição de carreiras profissionais e para a relação médico-paciente nas localidades que receberam tais estruturas, visto ambos passarem a conviver com novas organizações que vieram a realizar uma medicina apoiada mais em trabalho de equipe e em ambiente organizacional que na ação direta do médico profissional liberal.

Além disso, a interiorização das delegacias de saúde manteve certa correspondência com um movimento semelhante realizado pela Associação Paulista de Medicina (APM), principal entidade médica paulista da época, que então assume feição político-administrativa efetivamente estadual. Criada em 1930 para cuidar dos interesses médicos, essa associação passou por uma reorganização institucional promovida por uma importante reforma em seu estatuto no ano de 1948, que criou as seções regionais e sociedades filiadas à APM, situadas no interior do estado (Associação..., 1950). Tal mudança implicou que essas duas categorias de entidade assumissem a função de representar a APM nas cidades interioranas. Essas instâncias foram estabelecidas em cidades onde se percebeu a conveniência de reunir associativamente médicos das respectivas regiões que vieram a ter representação nas assembleias gerais da APM, a qual, pela reforma, tornou-se a principal instância deliberativa da entidade, o que impulsionou a participação de médicos do interior na associação. Dos 21 municípios com sociedades filiadas e seções regionais da APM, 12 também vieram a sediar delegacias regionais de saúde, ${ }^{1}$ revelando afinidades entre a interiorização políticoinstitucional da APM e o movimento de interiorização das políticas adhemaristas, o que indica uma favorável influência destas sobre o fortalecimento político-institucional da medicina em âmbito estadual.

Enfim, da questão de equiparação à criação da nova Secretaria de Saúde, percebemos mudanças que se conectavam a alterações mais amplas, inclusive internacionais, as quais produziam desde desenvolvimentos em saúde pública à expansão da medicina previdenciária e da chamada medicina de grupo. Tal ambiente determinou sérios desdobramentos à autonomia profissional médica (Freidson, 2001), os quais foram acompanhados com preocupação por destacadas lideranças profissionais paulistas, sobretudo o que denominaram "socialização da medicina". 


\section{A socialização sob a ótica médica}

Ilustres líderes da medicina de São Paulo reconheciam durante o governo Adhemar um significativo contexto sociopolítico para sua profissão, com o desenrolar de um processo que, embora de dimensões internacionais, atingia peculiarmente a realidade profissional local. Esse processo referia-se à progressiva socialização dos serviços médicos e sociais, que se transformavam em vários países, com implicações diretas sobre a prática liberal e a medicina realizada em organizações. Esses desenvolvimentos foram experimentados pelos médicos paulistas de forma mais imediata pela expansão de estruturas estatais e paraestatais de saúde, em meio ao despontar da medicina de grupo - que futuramente assumiria um relevante papel no setor de saúde como um todo. Os serviços mencionados enfatizavam atividades médicas realizadas a partir de equipes de saúde especializadas, em contexto organizacional, contribuindo para a expansão do trabalho assalariado.

Em palestra proferida na Associação Médica de Minas Gerais, em setembro de 1949, o então presidente da APM, doutor Jairo Ramos, ${ }^{2}$ tratou do tema da socialização, em foco no mundo inteiro. Para ele, não seria possível nem negar nem impedir o processo de mudança em curso. Contudo, defendia "discutir a oportunidade e as bases diretivas de sua realização, particularmente combater a socialização unilateral dos serviços médicos" (Ramos, 1949, p.71). Por outro lado, em discurso na cerimônia de posse do cargo de presidente da Sociedade de Medicina e Cirurgia de São Paulo (SMCSP), em março de 1950, o doutor José Pereira Gomes, ${ }^{3}$ disse que não era contra a socialização da medicina, que reconhecia existir e funcionar com êxito no mundo há muitos anos, mas acreditava que a medicina e suas associações deveriam ficar em alerta para que não se realizassem mudanças sem uma crítica precisa de seus elementos mais credenciados (O Estado..., 8 mar. 1950, p.8).

Tratando de processos de socialização em outros países, Jairo Ramos afirmou que, na Rússia, o Estado soviético fez o correto e deu bastante importância à medicina preventiva, orientação contemporânea à época e base dos serviços sociais e dos institutos de aposentadoria, tendo a assistência ao doente abrangido a assistência médica domiciliar, hospitalar e ambulatorial localizada nos centros de saúde, de modo a atingir tanto as zonas urbanas como as rurais. Os recursos que financiavam esse sistema provinham do Estado e de contribuições de seguros sociais. Contudo, Ramos argumentou (seguindo a opinião de Pereira Gomes) que o outro lado desse amplo processo foi a transformação da profissão médica em pura carreira estatal. Ramos entendia que alguns médicos podiam exercer a clínica privada, principalmente os mais competentes, mas os honorários que recebiam estavam sujeitos a altas taxas de imposto de renda: o médico era pago de acordo com o local em que exercia a profissão, sua idade e competência, sendo a remuneração fixa e não dependente da unidade de serviço prestado. Embora o Estado tivesse o trabalho médico em alta estima, Ramos considerava que, naquele país, o médico perdia quase totalmente sua individualidade e se subordinava ao Estado (Ramos, 1949, p.71).

Contrariamente ao caso russo, os dois dirigentes concordaram também que, na Inglaterra, a socialização dos serviços médicos teria sido fruto de uma ampla discussão do assunto no legislativo, na imprensa médica e na Associação Médica Britânica. Depois de livre discussão e concessões entre os envolvidos, Ramos assegurava que se havia promulgado 
uma lei que, ao criar o Serviço Nacional de Saúde, em 1948, "efetivou em paz a grande revolução pela qual modernizou a assistência médico-sanitária de seu povo" (Ramos, 1949, p.71). Inserido nesse regime, o médico inglês podia escolher sua atividade profissional. Se almejasse ingressar no serviço público como médico do Serviço Nacional de Saúde, deveria inscrever-se e indicar o posto ambicionado, ficando ao arbítrio de uma junta médica examinar o pedido e a necessidade de seu trabalho. Os médicos que trabalhassem para o governo recebiam bons salários, o que diminuía a necessidade de trabalho fora do âmbito estatal, mas estavam livres para exercer a clínica privada - desde que não atendessem pacientes sob seus cuidados nos serviços públicos. Assim, para Ramos, a socialização dos serviços médicos ingleses seguiu estritamente princípios democráticos. Contudo, Pereira Gomes destacou problemas no sistema inglês na distribuição de pacientes entre distintas regiões e deficiências no sistema hospitalar, com certas unidades superlotadas e médicos com excesso de trabalho.

José Pereira Gomes também tratou da socialização ocorrida no Chile, desde 1925, mas considerou que a situação dos médicos desse país deixava muito a desejar. Eles eram pagos por uma espécie de caixa com recursos oriundos de contribuições sociais. Tal caixa administrava os serviços médicos e exames laboratoriais e radiológicos gratuitos. O presidente da SMCSP considerava que, embora fosse limitado, o exercício da clínica privada ainda existia. Apresentando uma avaliação mais geral, Pereira Gomes acreditava que a medicina socializada era justificável desde que valorizasse o trabalho profissional, a evolução na carreira e o aperfeiçoamento técnico, com garantia de honorários condizentes com a posição social que reconhecia à carreira médica.

Por sua vez, Ramos destacou, ainda, a socialização dos serviços médicos pretendida pelo governo dos EUA. Em 1945, o presidente americano enviou uma mensagem ao Congresso nacional acerca da organização dos serviços médicos. Entre os itens tratados, assinalou: construção de hospitais, centros de saúde e outras instalações médicas acessíveis à população; expansão dos serviços de saúde pública e de saúde materno-infantil; pagamento antecipado de despesas médicas para pronta acolhida a todos os serviços, com a distribuição desses custos proporcional à expansão do seguro social compulsório existente; e, ainda, permissão aos pacientes para escolher o médico e o hospital que desejassem (estivessem integrados ou não ao sistema) e permissão aos médicos para também escolher seus pacientes e se participariam ou não do plano, integral ou parcialmente; enfim, existiria uma proteção contra perda de salário por doença ou incapacidade - mais relacionada com benefícios em dinheiro. $\mathrm{Na}$ condição de órgão executivo, haveria uma diretoria-geral com amplas atribuições de gestão do setor, que seria assistida por um conselho consultivo.

Segundo o presidente da APM, contra essa lei lutavam a Associação Médica Americana e a American Bar Association (associação dos advogados americanos), embora houvesse determinados médicos menos prestigiados que a apoiassem. A Associação Médica Americana afirmava que o plano prejudicava a medicina privada e implicava uma socialização perigosa, promovendo uma alteração nos serviços médicos somente verificada na URSS. Também considerava ditatorial a função de diretor-geral. Por sua vez, Pereira Gomes enfatizou as alegações de seus colegas americanos de que essas alterações reprimiam a livre iniciativa e o prestígio médico. 
Tais análises dos presidentes da APM e da SMCSP tocam em aspectos até hoje significativos da organização dos serviços de saúde. Os dirigentes tratam das relações entre: médico e paciente, prática liberal e serviços públicos de saúde, assistência médica e saúde pública, medicina curativa e preventiva. Além disso, é interessante observar como os dirigentes avaliam as distintas realidades nacionais abordadas: no caso russo, ambos concordam relativamente com as mudanças, mas se mostram contrários à falta de liberdade profissional do médico e à pressão negativa realizada pelo governo sobre a prática liberal. Quanto ao caso inglês, o presidente da APM entendeu que se tratava de uma revolução que modernizou a assistência médico-sanitária do país e que havia contado democraticamente com a participação dos médicos ingleses. Já Pereira Gomes acreditava que, embora houvesse liberdade para o médico na Inglaterra, as condições de trabalho eram questionáveis. Quanto à socialização norteamericana, o dirigente da APM não emitiu considerações mais claras e conclusivas, mas fez questão de apresentar não apenas as características da lei pretendida pelo governo americano, como a posição da Associação Médica Americana. De sua parte, Pereira Gomes apresentou as críticas de seus colegas americanos, também realçando a visão de sua categoria sobre o processo de socialização nos EUA.

Diante desse quadro, verificamos que ambos os dirigentes compreendem a socialização da medicina como um processo irreversível, mas que pode assumir feição particular conforme o país, e que seria imprescindível a participação médica organizada no processo. Pereira Gomes não aceitava que a medicina socializada fosse desequilibrada e unilateral, por gerar grave desigualdade de direitos e salários entre médicos. Jairo Ramos reconhecia a necessidade de organizar os serviços médicos em outras bases, dada a crescente complexidade dos meios diagnósticos e terapêuticos, que estavam encarecendo o serviço médico, deixando-o fora do alcance da maioria da população. Ramos aceitava discutir o problema, mas combatia a tendência que observava em seu país de uma socialização unilateral sem a anuência da categoria médica brasileira. Dessa maneira, se, de um lado, a socialização representava um processo que respondia a uma necessidade imperiosa, de outro, não estaria sendo acompanhada de uma modificação equilibrada para a profissão médica.

O líder da APM acompanhava com preocupação o desenvolvimento dos vários Institutos de Aposentadoria e organizações semelhantes, que estariam socializando a profissão médica, com evidentes prejuízos aos profissionais da clínica privada. Ademais, as várias organizações beneficentes de sua época estariam estendendo benefícios à custa do trabalho médico. E o Estado, com seus serviços de assistência pública, estaria estabelecendo concorrência com o exercício profissional privado. Com esse entendimento, Jairo Ramos combatia as organizações de serviços sociais ligadas à indústria e ao comércio, conhecidas como Serviço Social da Indústria (Sesi) e Serviço Social do Comércio (Sesc), que prestariam assistência médica aos operários e comerciários pela supressão progressiva da medicina liberal, mediante contratos de serviços a muito baixo preço. Para ele, a situação apresentava considerável complexidade, pois a população empobrecida não dispunha de recursos para a manutenção de sua saúde, o que demandava cuidados organizados naquela modalidade, mas o problema que reconhecia nisso era de que se estava socializando a medicina e os serviços de saúde à custa do trabalho médico, desconsiderando os demais fatores socioeconômicos influentes sobre a saúde do trabalhador (Ramos, 1949). O presidente da APM afirmava que os serviços 
sociais da indústria e do comércio e os vários Institutos de Aposentadoria e Pensões (IAPs) previdenciários pagavam na base do salário-mínimo, sendo essa referência insuficiente para as condições de formação e prestígio da categoria.

Contudo, Jairo Ramos também apontava erros cometidos pelos médicos brasileiros, que dificultariam igualmente essa situação - como a pletora de médicos nos centros de maior densidade populacional: na capital paulista, em 1949, existiriam 2.400 médicos para 23\% da população do estado, ao passo que, para os $77 \%$ restantes do interior, existiriam três mil profissionais. Ramos acreditava que a situação nos outros estados era semelhante. Assim, sugeria que os jovens médicos deveriam aderir ao seu apelo e assumir o que ele chamou de "espírito de bandeirantes da saúde", aceitando cuidar dos problemas de saúde das populações interioranas. Enfim, defendia a ação coletiva dos médicos brasileiros por meio da criação de uma Sociedade dos Médicos do Brasil, que participaria ativamente do processo de socialização em curso (Ramos, 1949).

Tratando dos mesmos problemas, encontramos a visão de outro influente médico paulista, talvez mais conhecido por sua atuação na política partidária que como profissional da medicina. Em matéria publicada na imprensa paulista em 1947 (O Estado..., 2 jul. 1947, p.5), encontramos uma análise da medicina daquela época realizada por Antônio de Almeida Prado. ${ }^{4}$ Essa análise se refere a um discurso proferido na solenidade de posse da nova diretoria do Departamento Científico do Centro Oswaldo Cruz, da Faculdade de Medicina da USP, evento ocorrido na APM. Nesse pronunciamento, Almeida Prado faz um balanço dos desenvolvimentos da medicina de sua época, destacando a importância da medicina de grupo, mas, principalmente, enfatizando a necessidade de maior participação do Estado no setor de saúde. É possível extrair do pronunciamento elementos que caracterizam, ao mesmo tempo, tanto a evolução técnica e organizacional da medicina quanto alguns fatores inerentes às relações internas ao grupo médico. Destaca-se a expansão não apenas de vários tipos de especialidades médicas como ainda de organizações públicas e privadas responsáveis por serviços de saúde. O pronunciamento revela ainda uma importante distinção no interior da medicina nos anos 1940 e 1950, ou seja, as diferenças entre clínicos liberais e médicos que realizavam seu trabalho em organizações de saúde, como na medicina de grupo, na saúde pública, na medicina previdenciária e na administração governamental em geral.

Sobre essa questão da relativa diversidade, à época, de perfis profissionais entre os médicos paulistas, é bom lembrar que, como assinalado, já existiam pelo menos três grandes instituições de formação médica em São Paulo. Conforme Márcia Regina Barros Silva (2001), no início dos anos 1930, havia no estado de São Paulo uma crescente demanda de estudantes por vagas no ensino médico, e todos os anos sobravam vários candidatos excedentes nos vestibulares da Faculdade de Medicina de São Paulo. Com o tempo, isso gerou uma mobilização desses estudantes no sentido de que se aumentasse o número de vagas. Para Silva, tal demanda foi a principal motivação para a criação de uma nova escola médica no estado, a Escola Paulista de Medicina, constituída em 1933, a terceira faculdade da área, juntando-se à Faculdade de Medicina anterior e à Faculdade de Higiene. A autora aponta, ainda, que essa demanda não estava relacionada apenas a candidatos oriundos de grupos de elite, mas também a candidatos das classes médias. 
Esses dados nos fazem afirmar que o pós-1930 apresenta relevante intensificação de mudanças na medicina paulista, como: aumento da especialização ocupacional; diversificação das instituições de formação profissional; maior participação estatal no setor; e pluralização em termos de origem social dos profissionais, tendo como uma de suas consequências um alargamento da base do grupo médico estadual. Acreditamos que tenha sido em meio a esse conjunto de mudanças, iniciadas alguns anos antes, que se pôde contextualizar não apenas a medicina paulista no governo adhemarista analisado como também as alterações em termos de políticas de saúde que esse governo empreendeu.

O pronunciamento de Almeida Prado revela ainda interessantes aspectos da ideologia profissional que permeavam a visão de pelo menos uma parcela bastante influente dos médicos de São Paulo, representada por aquela liderança médica e sua audiência na APM. Com efeito, Almeida Prado traceja uma visão clara sobre o papel da medicina, sua missão "socializadora" e sua relação com o Estado. Para ele, a medicina socializada e a medicina de grupo deveriam substituir a medicina liberal ou individualizada, de tal modo que a medicina planificada atentasse para os problemas socioeconômicos que afetavam a saúde de coletividades, aproveitando-se dos desenvolvimentos técnico-científicos, das diversas especialidades médicas e organizações de saúde (O Estado..., 2 jul. 1947, p.5). Contudo, essa visão acerca da participação do Estado na saúde e quanto à substituição da medicina liberal pela medicina socializada não era compartilhada, inteiramente, pelos dirigentes Jairo Ramos e José Pereira Gomes. Embora ambos acreditassem que a socialização da saúde fosse um processo irreversível, mostravam-se mais cautelosos quanto aos destinos da prática liberal, isto é, defendiam que o processo de socialização médica garantisse a liberdade do médico em aderir ou não aos serviços socializados. Essa relativa divergência evidencia que, embora uma associação profissional, como a APM e a SMCSP, consiga falar em nome da sua coletividade, sempre existem vozes mais ou menos discordantes, com maior ou menor influência sobre o grupo profissional (Freidson, 1996), matizando a ideologia do grupo. No entanto, apesar desse sinal de discordância, é claramente compreensível que, à época, a clínica liberal tivesse um considerável espaço na medicina paulista e que certamente possuísse interesses relevantes que deveriam ser considerados por suas lideranças.

Por outro lado, devido ao encarecimento dos serviços de saúde, decorrente dos desenvolvimentos técnicos de sua época, Almeida Prado, Ramos e Pereira Gomes concordavam que, para a difusão dos benefícios da medicina, principalmente no sentido da população empobrecida, era necessário o protagonismo estatal no setor. Tal defesa indica uma linha de continuidade no pensamento médico paulista entre a Primeira República e o pós-guerra, já que também os sanitaristas daquele período entendiam que o Estado deveria assumir uma posição central na oferta de serviços de saúde (Castro Santos, 2004; Hochman, 1998). Tal posicionamento político-ideológico e profissional aponta para uma atitude de relativa abertura da profissão médica paulista às necessidades e demandas sociopolíticas externas e substantivas, uma postura que, como sugerido, enquadra-se no espectro político-ideológico típico de grupos profissionais em certas condições contextuais: trata-se de uma postura que aproxima a política da profissão das demandas sociais da política partidária, entendimento que polariza em relação à simples crítica anterior à socialização da medicina, a qual se centrava 
mais nas necessidades profissionais em sentido estrito. Tal ideário evidencia, ao mesmo tempo, algo típico da ideologia profissional desses médicos e que é comum às profissões em geral, ou seja, comprometem-se com a prestação de serviços não apenas às elites, mas também à sociedade em geral, estabelecendo uma conexão entre a missão que associam ao grupo e a realização do bem comum.

Esses dados manifestam ainda que a profissão médica paulista, entre 1940 e 1950, possuía uma composição social mais diversificada, e as preocupações com os desdobramentos sociopolíticos da medicina apontam para uma posição que não se refere meramente à de uma elite profissional atenta às próprias necessidades de inserção no conjunto das classes dominantes. É bem verdade que não podemos desprezar as origens ou aspirações sociais de classe e suas possíveis influências sobre um grupo profissional, mas entendemos que, com o passar do tempo, houve no grupo médico paulista certa pluralização em termos de origem de classe de seus membros, com um aumento concomitante do número de profissionais, o que reforçou a organização e a autoimagem do grupo como profissão. Ou seja, a profissão médica paulista já vinha incorporando grupos sociais não oriundos de setores de elite, o que, em nossa visão, aponta no sentido da crescente incorporação de grupos de classes médias, o que resultou no reforço da mobilização dos médicos como grupo profissional com interesses e ideologia próprios, cada vez mais definidos a partir das necessidades da profissão como um todo à parte, e menos a partir dos condicionamentos ligados à estrutura de classes. Entendemos que esse movimento de profissionalização iniciou-se antes, mas foi favorecido pela pluralização em termos de origem social dos integrantes desse grupo e do crescimento de sua base em todo o estado.

O estado de São Paulo contava, ao final de 1949, com aproximadamente 5.400 médicos (Ramos, 1949, p.80), com diversas especialidades; além disso, existiam não apenas adeptos da prática liberal e privada, mas também uma crescente fração de médicos assalariados pelos serviços públicos de saúde, os quais, como já analisado, estavam em processo de expansão e interiorização no estado. Não por acaso, vimos que o período é marcado pela extensão do raio de ação da então principal entidade médica estadual, a APM, a qual, desde 1948 passou por um processo de interiorização político-institucional e de suas bases sociais, em um movimento relativamente paralelo à interiorização dos serviços sanitários estaduais adhemaristas. Entendemos que a organização particular da medicina paulista como profissão (Freidson, 2001) e parte de um movimento de maior abrangência da medicina brasileira representa um processo iniciado anteriormente ao período em foco nesta pesquisa; movimento que aconteceu desde, pelo menos, a Primeira República (Castro Santos, 2004; Hochman, 1998; Pereira Neto, 2001). Mas o processo de incorporação de setores médios à medicina paulista, iniciado antes e que se desenrola durante o governo adhemarista, favoreceu o fortalecimento da organização profissional da medicina.

Preocupações acerca da organização profissional dos médicos paulistas podem, contudo, ser evidenciadas desde antes do governo Adhemar que analisamos, com a criação da SMCSP (1895) e da APM (1930) - que, até o surgimento do Conselho Regional de Medicina de São Paulo, em 1957, atuaram como principais organizações associativas dos médicos do estado. Tais preocupações em termos de organização profissional ultrapassaram o momento de criação dessas entidades e extrapolaram fronteiras de questões meramente técnicas da atividade 
médica, com a atenção voltada para a participação do Estado no setor de saúde, em meio ao contexto mais abrangente do que denominaram "socialização da medicina".

Analisamos efetivamente essas preocupações na aludida questão de equiparação: uma luta que não se referia diretamente à medicina liberal, mas aos profissionais assalariados pelos serviços públicos de saúde. Tal movimento revelou uma composição de interesses e valores comuns capaz de mobilizar os médicos coletiva e politicamente, e que tais interesses e valores se estendiam aos dilemas da base do grupo profissional, já que a equiparação afetava diretamente o poder econômico e o prestígio dos médicos dependentes de uma inserção profissional baseada em carreira estatal - ou seja, principalmente médicos recém-formados ou com poucos anos de carreira e que ainda contavam com uma clientela privada pouco abrangente. Além disso, notamos as mesmas preocupações em relação às ambivalentes influências entre a interiorização da APM e a politização e interiorização da nova secretaria de saúde adhemarista. Dessa maneira, os médicos paulistas reagiram como uma verdadeira coletividade profissional e se mobilizaram ativamente quanto à forma como as inovações na saúde de seu tempo aconteciam.

\section{Considerações finais}

Em nossa investigação, notamos uma ambivalente convivência ideológica entre a defesa médica no sentido de uma maior participação estatal no setor de saúde e temores quanto ao consequente assalariamento profissional. Vimos também os ambivalentes esforços médicos de enfrentamento das mudanças na saúde, diante dos dilemas apresentados pelas políticas de saúde adhemarista. Mas, apesar dessas ambivalências difíceis de inexistir naquele contexto político-profissional, entendemos que a medicina paulista possuía interesses e ideologia claros e comuns, e que cada vez mais se organizava profissionalmente. Embora já se notasse uma composição profissional mais diferenciada no período investigado, não notamos no grupo médico uma oposição estanque de interesses e ideias entre elite e base profissional ou entre os diversos setores e especialidades. Em realidade, os médicos paulistas realizaram um esforço de fortalecimento da coesão interna ao grupo, a fim de enfrentar os reflexos da denominada socialização da medicina e os dissabores da contraditória relação com o adhemarismo.

Finalmente, gostaríamos de salientar que aqui se investigou o governo populista de Adhemar de Barros a partir de referenciais conceituais da sociologia das profissões, que nos ofereceu valiosas contribuições para o estudo dessa expressão do populismo brasileiro.

\section{NOTAS}

* Este artigo apresenta resultados da dissertação de mestrado defendida em 2010 (Almeida, 2010), apoiada por bolsa da Coordenação de Aperfeiçoamento de Pessoal de Nível Superior (Capes) e Fundação de Amparo à Pesquisa do Estado de São Paulo (Fapesp).

${ }^{1}$ Seguem os municípios do interior com entidades regionais da APM - aqueles com asterisco também vieram a sediar delegacias de saúde: Araraquara*, Assis, Barreto*, Bauru*, Botucatu*, Catanduva, Jaú, Jundiaí, Ourinhos, Piracicaba, Piraju, Rio Claro, Taubaté* e Tupã. Já os municípios com sociedades locais filiadas à APM eram: Campinas*, Marília*, Presidente Prudente*, Ribeirão Preto*, São Carlos*, São José do Rio Preto* e Sorocaba*.

${ }^{2}$ Jairo de Almeida Ramos (1900-1972) formou-se na Faculdade de Medicina e Cirurgia de São Paulo e foi presidente da APM entre 1945-1952 e 1955-1956. Trabalhou na Santa Casa de Misericórdia de São Paulo 
(de onde foi também diretor clínico), no Hospital São Luiz Gonzaga, especializado em doenças pulmonares e no Instituto de Higiene de São Paulo, além de atender em consultório particular. Presidiu a Sociedade de Medicina de São Paulo em 1939-1940, tendo sido patrono da cadeira n.75. Livre-docente da Faculdade de Medicina da USP e professor e diretor da Escola Paulista de Medicina, ajudou a fundar a Sociedade Brasileira de Cardiologia, sendo seu presidente em 1955-1956. Foi fundador e editor dos Arquivos Brasileiros de Cardiologia, participou da criação da Associação Médica Brasileira, da Revista Brasileira de Medicina e do Conselho Regional de Medicina do Estado de São Paulo. Foi sócio e fundador da Associação Brasileira de Escolas Médicas. Para mais informações, ver: http://www.academiamedicinasaopaulo.org.br/?pg=biografia\&idioma=1.

${ }^{3}$ A Sociedade de Medicina e Cirurgia de São Paulo surgiu em 1895 com o objetivo de cuidar dos interesses e do congraçamento da classe médica do estado. Em 1953, veio a denominar-se Academia de Medicina de São Paulo, como é conhecida hoje. O doutor José Pereira Gomes foi seu presidente em 1927-1928 e 19501951. Diplomou-se médico e iniciou sua carreira, em 1914, como médico e cirurgião na Santa Casa de Misericórdia de São Paulo. Mais tarde, complementou sua formação na Europa. Após seu retorno, tornou-se assistente da disciplina de oftalmologia da Faculdade de Medicina e Cirurgia de São Paulo. Pereira Gomes também contribuiu para a fundação do Instituto Padre Chico, obra de benemerência aos cegos paulistas. Faleceu em São Paulo, em 1968. Foi patrono da cadeira n.80 da Academia de Medicina de São Paulo. Para mais informações, ver: http://www.academiamedicinasaopaulo.org.br/?pg=biografia\&idioma=1.

${ }^{4}$ Antônio de Almeida Prado, além de profissional influente, candidatou-se ao governo paulista nas eleições de 1947, pelo PSD, perdendo o pleito para Adhemar de Barros. Membro da APM e professor da Faculdade de Medicina da USP, além de reitor dessa universidade entre outubro de 1946 e janeiro de 1947. Foi ainda patrono da cadeira n.102 da Sociedade de Medicina e Cirurgia de São Paulo. Para mais informações, ver: http://www.academiamedicinasaopaulo.org.br/?pg=biografia\&idioma=1.

\section{REFERÊNCIAS}

ALMEIDA, Fabio de Oliveira.

Reforma sanitária e política paulista: as relações entre o processo de profissionalização dos médicos de São Paulo e políticas de saúde do governo estadual de Adhemar de Barros (1947-1951). Dissertação (Mestrado em Sociologia) - Universidade Federal de São Carlos, São Carlos. 2010.

ASSOCIAÇÃO...

Associação Paulista de Medicina. Estatutos aprovados em assembleia geral reunida em 2 de julho de 1948 e reformados em assembleia geral reunida em 26-29 de janeiro de 1950. Revista Paulista de Medicina, v.36, n.5, p.87-97. 1950.

CASTRO SANTOS, Luiz Antônio de.

Poder, ideologias e saúde no Brasil da Primeira República: ensaio de sociologia histórica. In: Hochman, Gilberto; Armus, Diego (Org.). Cuidar, controlar, curar: ensaios históricos sobre saúde e doença na América Latina e Caribe. Rio de Janeiro: Fiocruz. p.249-293. 2004.

FERREIRA, Jorge.

O populismo e sua história: debate e crítica. Rio de Janeiro: Civilização Brasileira. 2001.

FREIDSON, Eliot.

Profissão médica: um estudo de sociologia do conhecimento aplicado. São Paulo: Unesp; Porto Alegre: Sindicato dos Médicos. 2009.
FREIDSON, Eliot.

Professionalism: the third logic. Cambridge: Polity Press. 2001.

FREIDSON, Eliot.

Para uma análise comparada das profissões: a institucionalização do discurso e do conhecimento formais. Revista Brasileira de Ciências Sociais, n.31, p.141-145. 1996.

FRENCH, John. $O A B C$ dos operários: conflitos e alianças de classe em São Paulo: 1900-1950. São Paulo; São Caetano do Sul: Hucitec. 1995.

HALLIDAY, Terence.

Politics and civic professionalism: legal elites and cause lawyers. Law and Social Inquiry, n.24, p.1013-1060. 1999.

HOCHMAN, Gilberto.

A era do saneamento: as bases da política de saúde pública no Brasil. São Paulo: Hucitec; Anpocs. 1998.

O ESTADO...

O Estado de S. Paulo. 8 mar. 1950.

O ESTADO...

O Estado de S. Paulo. 16 fev. 1949.

O ESTADO...

O Estado de S. Paulo. 30 jan. 1949. 
O ESTADO...

O Estado de S. Paulo. 26 jan. 1949.

O ESTADO...

O Estado de S. Paulo. 8 fev. 1948.

O ESTADO...

O Estado de S. Paulo. 6 fev. 1948.

O ESTADO...

O Estado de S. Paulo. 2 jul. 1947.

OLIVEIRA, Jaime A. de Araújo; TEIXEIRA, Sonia M. Fleury.

(Im)Previdência Social: 60 anos de história da Previdência no Brasil. Petrópolis: Vozes; Associação Brasileira de Pós-Graduação em Saúde Coletiva. 1985.

ORTIZ, Renato (Org.).

Pierre Bourdieu: sociologia. São Paulo: Ática. 1983.

PEREIRA NETO, André de Faria.

Ser médico no Brasil: o presente no passado. Rio de Janeiro: Fiocruz. 2001.

PORTER, Roy (Ed.).

Cambridge - história da medicina. Rio de Janeiro: Revinter. 2008.
RAMOS, Jairo.

Considerações sobre a socialização da profissão médica no Brasil. Revista Paulista de Medicina, v.35, n.4, p.71. 1949.

SAES, Décio.

Classe média e sistema político no Brasil. São Paulo: Tomaz de Aquino Queiroz. 1985.

SAMPAIO, Regina.

Adhemar de Barros e o PSP. São Paulo: Global. 1982.

SCHRAIBER, Lilia Bilma.

O médico e seu trabalho: limites da liberdade. São Paulo: Hucitec. 1993.

SILVA, Márcia Regina Barros.

O ensino médico em São Paulo e a criação da Escola Paulista de Medicina. História, Ciências, Saúde-Manguinhos, v.8, n.3, p.541-566. 2001.

WEFFORT, Francisco Correia.

O populismo na política brasileira. Rio de Janeiro: Paz e Terra. 1978. 